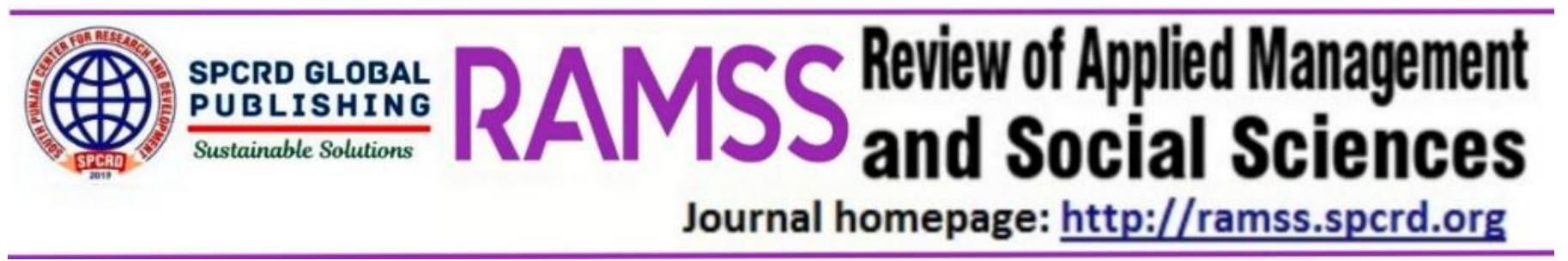

\title{
Advanced Technologies for Supporting Dispute Resolution: An Analysis
}

\author{
${ }^{a}$ Serkan Kaya, ${ }^{b}$ Muhammed Danyal Khan, ${ }^{c}$ Rao Imran Habib
}

a PhD from Brunel University, London College of Business, Arts and Social Sciences, Department of Politics, History and the Brunel LAE School, United Kingdom

b PhD Scholar, Brunel University, London College of Business, Arts and Social Sciences, Department of Politics, History and the Brunel LAE School, United Kingdom

${ }^{\mathrm{c}}$ Assistant professor, Gillian Law College Bahuddin Zakariya Multan, Pakistan

Corresponding author's email address: raoimran@bzu.edu.pk

\begin{tabular}{|c|c|}
\hline ARTICLE DETAILS & ABSTRACT \\
\hline $\begin{array}{l}\text { History: } \\
\text { Accepted: } 22 \text { June } 2019 \\
\text { Available online: } 30 \text { June } 2019\end{array}$ & $\begin{array}{l}\text { Current Traditional litigation in courts is still considered as the } \\
\text { main dispute resolution forum for civil disputes. However, as a } \\
\text { result of the digital revolution of society, traditional litigation }\end{array}$ \\
\hline $\begin{array}{l}\text { Keywords: } \\
\text { Artificial Intelligence, } \\
\text { Intelligence Machines, Online } \\
\text { Dispute Resolution }\end{array}$ & $\begin{array}{l}\text { has become very slow, expensive, formal, and complex. To } \\
\text { meet the requirement of the digital age regarding the } \\
\text { resolution of disputes, Online Dispute Resolution which is a } \\
\text { combination of Alternative Dispute Resolution with } \\
\text { Information Communication Technology, has become the new }\end{array}$ \\
\hline $\begin{array}{l}\text { JEL Classification: } \\
L 60, L 64, L 69\end{array}$ & $\begin{array}{l}\text { trend for resolving disputes. This article critically examines the } \\
\text { use of Artificial Intelligence in ODR and gives some successful } \\
\text { examples of global ODR services. }\end{array}$ \\
\hline DOI: 10.47067/ramss.v2i1.14 & $\begin{array}{r}\text { (C) } 2019 \text { The authors. Published by SPCRD Global Publishing. This is an } \\
\text { open access article under the Creative Commons Attribution- } \\
\text { NonCommercial } 4.0\end{array}$ \\
\hline
\end{tabular}

\section{Introduction}

The impact Technology not only changes rapidly; it changes so quickly that many of us do not even recognize these changes. Many people have not yet understood how fast and deep the current digital revolution is, or how quickly it changes existing habits and institutions. It is always heard about the driverless car, robot lawyer. It is known that technology has something to do with it. But the future is approaching much faster than it is thought. Advanced technology has changed the majority field of modern life and changed the way of interaction of people with each other in profound ways. Computers are utilized by society for many communications because especially mobile phones and tablets are so convenient and comfortable to operate communications. Over 4.5 billion people use the internet, which is $58 \%$ of the world's population (Internet World Stats 2019) and 22 billion devices worldwide connected to the internet at the end of 2018 (Strategy Analytics 2019).

Postman (1998) explained the impacts of technological change as follows:

[a] technological change is a trade-off. I like to call it a Faustian bargain. Technology giveth and 
technology taketh away. This means that for every advantage a new technology offers, there is always a corresponding disadvantage. The disadvantage may exceed in importance the advantage, or the advantage may well be worth the cost. Now, this may seem to be a rather obvious idea, but you would be surprised at how many people believe that new technologies are unmixed blessings. You need only think of the enthusiasm with which most people approach their understanding of computers. Ask anyone who knows something about computers to talk about them, and you will find that they will, unabashedly and relentlessly, extol the wonders of computers. You will also find that in most cases they will completely neglect to mention any of the liabilities of computers. This is a dangerous imbalance, since the greater the wonders of technology, the greater will be its negative consequences.

Inevitably, the practice of dispute resolution has been affected by these advanced technologies. Not only the way of communication but also the way of conflict and resolution are changing. While the majority field of modern life is being changed, people`s expectations are changing about how disputes should be resolved. People immediately think that a problem should be reported at any time of day and get quick and resolved transparently and efficiently (Rule, 2015).

To meet the legal requirements of the globalized era, particularly in the dispute resolution area, revision of the traditional system is unavoidable. ICT has become a fundamental part of the dispute resolution process and is a crucial element of Online Dispute Resolution (ODR). Recently, the role of it has become noticeable in the provision of traditional dispute resolution services (Lodder and Zeleznikow, 2010).

This paper critically examines advanced technologies for supporting dispute resolution. The first part of this paper deeply analyses Artificial Intelligence concerning the law area, especially dispute resolution, and points out how ODR can or could be improved. The second part of this paper gives some successful examples of global ODR services.

\section{Advanced Intelligent Technologies for Dispute Resolution}

While technology has developed, it may have been wondered whether humans will be replaced by artificial intelligence devices regarding performing complicated, repetitive, and interactive tasks such as city planning, aviation, dispute resolution, and traffic management. Computer algorithms and mechanisms may better perform these complex tasks than the human mind. The fallibility is narrow, the work is done more quickly, and the training essential is minimal. Siri on iPhone, S-Voice on Samsung, anti-lock brakes in a car, learning the road conditions, Amazon's recommendations on things that consumers might like are Artificial Intelligence that are used in daily life without noticing.

In today`s world, nanotechnology and neurotechnology have already made machines more intelligent. Artificial Intelligence is frequently forcing the limits of traditional areas. Corporate technology giants, software developers, computer programmers are leading on reform and establishing the pace of new world order. According to the prediction of The Guardian, driverless cars will be seen on the streets very soon. (The Guardian 2015). Currently, more than 1,400 driverless cars are in testing by more than 80 companies in the US. (TechCrunch 2019) Similarly, 3D printers make threedimensional solid objects from a digital file.

Those developments unavoidably raise questions and involve some risks. For example, if a child abruptly runs into the street, the driverless car may need to make split-second decisions. Those decisions reveal legal questions; who is responsible if the car performs the wrong decisions? How does 
the car decide? In the same manner, the Royal Mail launched a 3D printer. Who is ownership of the items which the $3 \mathrm{D}$ printer produces? Who is responsible if the item is unsafe? In other words, if an Artificial Intelligence machine (robots, avatars) commits a crime or makes a wrong decision, who is liable for the actions taken?

In an era of intelligent technology, justice, and the legal system have commenced to adopt the use of technology and benefit from Artificial Intelligence. For example, 90\% of eBay disputes are handled with no human intervention.

\section{Artificial Intelligence in Dispute Resolution}

The emergence of Artificial Intelligence was in the 1950s to program the facts and rules into the machine (Bock, 1985). John McCarthy (2007), was one of the founders of the discipline of artificial intelligence, refers that 'Artificial Intelligence is the science and engineering of making intelligent machines`. The Cambridge dictionary defines it as:

[t]he study of how to produce machines that have some of the qualities that the human mind has, such as the ability to understand language, recognize pictures, solve problems, and learn.

AI has two corresponding elements: the physical form of the device and the intellectual capacity of the software (Science Daily, 2008). The differentiation between these two elements is defined by Larson (2010) as:

[a] device can either behave intelligently as a result of automated or human-controlled directions, or a device literally can be intelligent in the sense that it requires no external influence to direct its actions.

The more immediately attainable aim is to produce a smart device. Because it is believed that humans are smartest classes, it should not be unexpected that a notable number of AI studies regarding this main aim include smart machines that seem like humans especially, robots. Robotics experts and professionals produce the physical descriptions of people that imitate people's actions and even the appearance of people. Robots are being developed that duplicate human appearing and movement amazingly and perfectly. (Larson, 2010).

In the technology era, it comes to humans` minds that can those devices, are intelligent, be created? If so, what kind of roles can be taken by those devices in ODR processes? Will AI devices (robot or avatar) support the conversations and disclosures required for successful problem-solving (Larson, 2010)? Can human mediators, arbitrators, and problem solvers be replaced by robots or avatars? Can humanoid robots, attractive avatars help parties to come to an agreement or find a solution for their problems? Do robots and avatars view, move, performance, analyse, and reflect better than people (Larson, 2010)? To find answers to those questions, some critical human capabilities of robots and avatars such as commitment emotion, cooperation, and social relationship should be discussed (Rich and Sidner, 2009). Are AI devices getting smarter than humans? Some specialists consider that this kind of "intelligence explosion" will emerge and we will develop smarter machines by the end of the human period. (Markoff, 2009)

\section{How Can Artificial Intelligence improve ODR?}

One of the practical effects of globalization is that both clients and practitioners usually expect to resolve disputes in the shortest and simplest way. Thus, their expectation is that as far as possible ICT 
should be used in the advanced stage. In view of this paper, there are two ways to improve ODR with the use of Artificial Intelligence. The first one is the use of intelligent machines that behave efficiently and handle disputes without human intervention such as robots and avatars. The second one is the intellectual capacity of software and some devices which need an external influence to control directions such as Case-based Reasoning Systems.

\subsection{Intelligent Machines}

Firstly, it should be said that intelligent machines, which are used to improve ODR may bring some disadvantages to it. However, the use of intelligent machines is the initial phase and being improved with each passing day. It is surely beyond doubt that each recent development fills prior gaps and reveals some new problems. The use of robots or avatars in the dispute resolution system will majorly remove some obstacles and challenges of ODR. Low cost will, even more, decrease compared to human actions. With robot arbitrators or mediators, the issue of "an impartial and independent third party" will disappear. Robots will be able to resolve the dispute regarding rules or states and languages around the world.

\subsection{Intelligent Decision Support System}

In the field of law, it is known as legal decision support systems. Nevertheless, the use of it is still recent, and there are not any advanced systems to meet the requirements of the globalized era in the legal arena. However, in order to meet those requirements, at least the ones shall be developed.

A decision support system receives, stocks, utilities, accepts, and performs information relevant to the decisions being made. Its capacities are described by the types of facts with which it can operate, how it can express these various types of knowledge, and its functions for processing these representations.

When it is considered the difficulty of the legal domain, legal decision support systems can be considerably beneficial, particularly if one thinks the immense amount of knowledge that parties, and neutrals must examine in certain complicated cases to take a resolution (Lodder and Zeleznikow, 2010). Without using any supporting tools, examining all this knowledge is not an efficient method that spends much time, getting slow the legal processes (Carneiro, Novais, Andrade, Zeleznikow, and Neves, 2014). Furthermore, some parties may not be at comfort with certain kinds of information, having difficulty to make best decisions.

These systems have the capability to examine related facts input by the parties alongside legal knowledge such as norms and regulations or prior known cases to take uncomplicated legal decisions. Some sectors have more significantly used decision support systems. Social security systems use these systems to decide whether an unemployed individual should receive a benefit in kind. When a client applies to a bank to grant a loan, with the help of these systems the bank more efficiently takes a decision. It is seen in these cases that human experts generally supervise results. Decision support systems are not automated systems that issue outcomes. These systems are based on significant information, issue justified suggestions, and collect information that can be useful for taking a result process (Wahab, Katsh, and Rainey, 2012).

\subsection{Expert System}

Computer-based information and communication have started to play a frequently prominent part of the legal system. One example of them is the Expert System. The feasibility of Expert System is not suitable for the whole of the law. In some areas of law such as dispute resolution, are seen that the 
use of Expert System facilitates practitioners`and problem solvers` work in modern life. Expert systems in law vary from legal information retrieval systems in that while the latter is defined to "raw legal data" that is, the text of statutes, case reports, and so on, the former try to embrace both propositions of information about law and methods for reasoning with that information (Susskind, 1988).

Expert System is described by Susskind as computer programs that have been formed in that they are skilled of functioning at the level of human experts in given fields (Allwood, 1989; Susskind, 1987). In that sense, humans design, train and tweak such systems that must incorporate a depth and richness knowledge which will provide humans to perform at such level (Carneiro, Novais and Neves, 2014).

Expert System is intelligent computer programs, to solve problems and make decisions, based on knowledge of its duty and relevant rules or procedures for using information. Both the information and the related are performed from the experience and relevant past cases in the area.

\subsection{Knowledge-Based System}

Knowledge is a broad term that there are many types of it such as explicit knowledge, factual knowledge, procedural knowledge, commonsense knowledge, domain knowledge and so on, and many different forms of obtaining it. Some knowledge may come from a single source and some of it may be collected from several ones. Moreover, depending on the technology amount of knowledge is spreading. In the information age, the storage of human brain is not capable to fully utilize (Sajja and Akerkar, 2010). The ability of the intelligent systems allows documenting of expert knowledge and utilize the knowledge to solve problems in a cost-effective way. Knowledge based systems is one of these intelligent systems. Knowledge based system is defines by Business Dictionary as:

[s]oftware that uses artificial intelligence or expert system techniques in problem solving processes. It incorporates a store (database) of expert knowledge with couplings and linkages designed to facilitate its retrieval in response to specific queries, or to transfer expertise from one domain of knowledge to another.

Regarding the legal area, such techniques are essential, mainly to describe a type that can deal with a diversified group of knowledge that may involve, but is not limited to parties' data, standards, former cases, matters or debates. These methods are also crucial when such data must be filed in an electronical environment that allows for high-speed and cost-effective reuse. When information is saved in a regular and well-defined method, it allows for the growth of automated processes (Carneiro, Novais and Neves, 2014). The growth of systems that can voluminously cope with vast amounts of information is, in fact, one significant advancement that lawyers can use to handle disputes. Furthermore, knowledge-based schemes can be created to embrace either statute law or case law (Carneiro, Novais and Neves, 2014). The central motive behind to have Knowledge-based Systems in the legal field is its ability to represent norms and judgment. Systems can be improved to create new knowledge-based actions or results.

\subsection{Case Based Reasoning}

Case-based reasoning can be referred as a problem solver paradigm to understand conflicts with using past experiences (Kolodner, 1992). Case-based reasoning can mean adapting past solutions to meet new requirements; using previous cases to define new conditions; using past cases to analysis new 
resolutions; or reasoning from examples to understand a new situation or perform a balanced solution to a new problem (Kolodner, 1992). The principal theory is that if a new problem resembles the old one, it will have an alike outcome. This method is usually recognized in humans and is inherently associated with learning processes. Generally, this procedure includes the capacity to examine two cases and realize that if they are similar, they will have the same result (Carneiro, Novais and Neves, 2014). Accordingly, the first thing is to do be done is to select among all the incomparability that describes a case, which are the ones that are beneficial to define the identity between two cases. In several cases, dealing with all the features studied in the discourse universe and their potential value ranges is not calculable or efficient (Carneiro, Novais and Neves, 2014).

According to Kolodner, (1992) , a Case-based Reasoning method is usually designed in four stages namely: Retrieve, Reuse, Revise and Retain. In the first stage, the problem is examined and the similar cases are retrieved from the memory and adjusted in accordance with a value of identity (Aamodt and Plaza, 1994). This type of similarity depends on the problem area, however, usually is similar to the difference between the sums of the different characteristics that describe the cases. In the Reuse stage, the resolution from the prior case is planned to the purpose problem, which may include adjusting the resolution to some special necessity of the new issue (Aamodt and Plaza, 1994). This stage is inevitable since there is no case in the case memorial that accurately meets the characteristics of the new one. Theoretically, it would not be impossible to produce as many cases as required to satisfy all the various qualities. Nevertheless, the size of such a case base would be infeasible. Therefore, an inevitable compromise between some cases filed and the values of similarity accomplished. In another stage, the resolution is examined or fabricated to decide the outcome of its utilisation. It may be reasonable that the outcomes are not satisfied as demanded, which should guide to the examination of the steps taken. At the final stage, the resolution utilised may be deposited in the case memory, along with the explanation of the new case, contributing to the advancement of the case memory.

Cased-based Reasoning is clearly useful in the legal area and provides that the capability to expect a result is a crucial part of the legal advice. A lawyer usually reviews prior similar cases and their results to attempt to guess the result of a new one. The assumption of legal precedence describes a case that creates a rule or law that should be utilised by lawyers when determining succeeding relevant matters. (Carneiro, Novais and Neves, 2014).

It is clearly seen that Cased-based Reasoning systems is already one of the most used approaches for not only online dispute resolution system but also traditional system. Cased-based Reasoning methods are particularly useful in common law systems.

\section{The Major Online Dispute Resolution Providers}

\section{1 eBay and PayPal}

eBay is one of the most known examples of ODR. In comparison with some other ODR providers, eBay dispute centre only concerns e-disputes that arise from eBay related online transactions. eBay is not principally an ODR service provider but a company that provides ODR service into its service portfolio regarding users' satisfaction and confidence. It was founded in 1995. eBay is an American multinational corporation and has become the world's largest online marketplace where users buy or sell almost anything (The History of eBay, 2015). Currently, eBay has 177 million involved users in 190 markets and more than a billion total listings (eBay, 2019).

E-commerce designers have asserted that e-commerce presents some challenges to the buyers and sellers (Cortes, 2012). Unlike traditional transaction, customers have no chance to "meet" their 
seller, and mutually. Even online retailers try to provide online system of trade satisfaction, consumers are no confident to buy online before getting items, particularly for high value items (Raymond, 2014).

Because of some challenges of e-commerce and hesitant of online users, eBay aims to remove barriers; to promote customers confidence when they do business or use service online. This aim shows e-Bay e-trust policies that purpose to make buyers and sellers comfortable in buying or selling items online (Wang, 2014).

eBay`s use of ODR started in March 1999 as a pilot project to see the feasibility of mediate disputes between buyers and sellers (Rabinovich-Einy, and Katsh, 2012). Those years, on behalf of communication face to face, email was used (Katsh, Rifkin, and Gaitenby, 2015). Two hundred disputes were resolved in a two week period(Katsh, Rifkin, and Gaitenby, 2015). eBay determined to maintain to offer mediation to its users and assigned dispute resolution to an Internet start-up and selected SquareTrade.com to be eBay`s preferred dispute resolution provider. SquareTrade, is a private company, was leading ODR provider for eBay. However, as in 2008, eBay stopped using SquareTrade for dispute resolution (SquareTrade, n.d). At the moment, the majority of ODR services have been taken over by eBay and PayPal dispute resolution services, which now resolves the remarkable number of disputes a year (Rule, 2015). The benefit of dealing with a large number of disputes is that the similar matters appear several times, so it is possible to categorize the disputes into different parts.

Ultimately, eBay developed as an internal automated negotiation system for particular types of disputes. eBay realised that disputes mainly occur because of miscommunication. eBay Resolution Center offers some specific types of disputes to find users`exactly problems such as 'item not received `, 'item not as described` and `unpaid item` (eBay, n.d).

Since the development of the internal automated negotiation systems, eBay has maintained to improve its ODR mechanism such as expanding initially to PayPal (Raymond and Stemler, 2015). PayPal was established in 1998 as a security software company for handheld devices. PayPal had its Initial public offering in 2002 (PayPall, 2019). Later that year, PayPal was owned by eBay. However, eBay spun off PayPal in July 2015 (BBC, 2015). PayPal is one of the worlds`s largest online financial transaction broker. PayPal has 267 million active users in 202 countries and allows users to transfer, receive and hold funds in 25 currencies worldwide (PayPall, 2019).

The eBay`s ODR process starts when a party submits a complaint. Then, the claimant is required to complete a web-based standard claim form to classify the type of dispute and to offer a list of common resolutions. The other party is then communicated by email, where she or he is informed about the complaint process and is questioned whether she or he wants to participate. Individuals are frequently enthusiastic to participate because this is the only way in which the buyer can get redress and the seller can get a positive feedback (Cortes, 2014). When the other party replies and chooses the resolutions that she or he favours, and when both parties accept the same resolution, the dispute is resolved. If the parties do not reach an agreement, the parties are put into a negotiation environment (Cortes, 2014).

If the parties cannot reach an agreement through eBay`s ODR Platform, then The Resolution Services team, which is operated by eBay`s Customer Support section handles the claim (Cortes, 2014). With the help of parties, who provide supporting information, this team will deal with the disputes and make a decision on whether the claim is upheld (Cortes, 2014). 


\subsection{ICANN and WIPO-UDRP}

The Internet Corporation for Assigned Names and Numbers (ICANN, 2014) is an international non-profit organization that is responsible for organizing the new generic top-level domains and the operation of root name servers such as .com, .net and .org,. The World Intellectual Property Organization (WIPO, 2015) is a global forum that is responsible the growth of a balanced and practical international intellectual property (IP) system.

Although the WIPO operates many tasks, WIPO Arbitration and Mediation Centre was established in 1994 that to promote and provide time and cost efficient services for the resolution of disputes between private parties concerning intellectual property and technology (WIPO, 2015). The Centre is independent and is assisted by external experts in international dispute resolution.

The Uniform Domain Name Dispute Resolution Policy (UDRP) was adopted by under leadership of ICANN for all ICANN-accredited registrars in 1999. WIPO is accredited by ICANN as a domain name dispute resolution service provider. UDRP is a mechanism that resolves disputes between domain name owners and trademarks holders. Since then, WIPO Center has been presenting ODR services that have administered 46,000 UDRP based cases filed, encompassed 86,000 domain names.

Paragraph 4(a) of the UDRP Policy regulates a threefold test which needs a rights holder to show that:

(i) the domain name registered by the domain name registrant is identical or confusingly similar to a trademark or service mark in which the complainant (the person or entity bringing the complaint) has rights; and (ii) the domain name registrant has no rights or legitimate interests in respect of the domain name in question; and (iii) the domain name has been registered and is being used in bad faith

WIPO cases in the past year were linked to patents, trademarks, software, research and development and franchising, and filed with the WIPO Center by parties on the basis of prior contract clauses as well as submission agreements. Cases filed after 1 June 2014, were administered under the new WIPO Mediation, Arbitration, Expedited Arbitration and Expert Determination Rules.

In a recent development, the WIPO Center provides services for specific sectors: (a) Collaboration with Intellectual Property Offices (b) Fast-Track Procedure (c) Trademarks Dispute Resolution (d) Patents in Standards Dispute Resolution (e) Research and Development Dispute Resolution (f) Franchising Dispute Resolutions (WIPO General Assembly, 2015).

\subsection{Cybersettle}

Cybersettle is a private company holding patents its process of `blind binding`, was established in 1996. Cybersettle has been working online settling disputes since 1998. Initially, Cybersettle focused on the resolution of disputes between insurance companies and their clients but later extended its solution to financial services, law firms, corporations, public services, professional service companies assisting in the settlement of disputes between citizens and municipalities (Cybersettle, 2019 and Cortes, 2014). Since 1998, Cybersettle has handled more than 200.000 transactions and has resolved cases worth a total amount $\$ 1.9$ billion. That's the number of dollars show that currently, Cybersettle is currently one of the major online settlement and payment solution web-based companies.

In 2006, The American Arbitration Association (AAA), is a not-for-profit organization and offers services to people and companies who wish to have a solution through ADR, and Cybersettle declared a 
strategic alliance that offer parties to use both companies' ADR and ODR services. AAA has managed about 4.1 million ADR cases since its founding.

Recently, Cybersettle has become common in the medical care sector in the United States, which amounts to $\$ 2.7$ trillion. PayMD, was launched by the founders of Cybersettle in 2012, is an online solution to settle medical bills. CyberSettle's website asserts that its purpose is:

"to provide our clients with cloud-based solutions that motivate and empower patients to engage, settle and pay their medical bills - resulting in increased revenues, faster and at a lower cost than traditional methods" (Cortes, 2014)

\subsection{Modria}

Modria was founded in 2011 by Colin Rule and Chittu Nagarajan. Colin Rule was the head of first eBay`s ODR Center, which process over 6o million disputes over a year, from 2003 to 2011. The principal aim of Modria is to offer ODR services for any size and type of dispute. Modria provides most common methods of ODR, including diagnosis, (MODRIA.ORG, 2019). Moreover, Modria provides a case management and workflow system that manages case intake, document generation and management, scheduling, reporting, and status messaging (Online Dispute Resolution Advisory Group, 2015).

In 2014, Modria announced that AAA has chosen Modria as an ODR services to handle its New York No Fault case load. It is expected that more than a hundred thousand cases, particularly road traffic accident cases, will be handled by the platform on an annual basis (Cortes, 2014). Furthermore, in the State of Ohio, tax assessment disputes are handled by Modria's dispute resolution system, automating a subset of the tax court (The Civil Justice Council, 2014). In the Netherlands Modria`s system automates divorce proceedings.

\section{Conclusion}

In recent decades, with the advent of ICT, many sectors such as marketing, commerce, banking, law, shopping and human sources have gone to digital. There are two critical questions; will the humans be replaced by artificial intelligence devices and how humans and machines are evolving to work together. In dispute resolution system, traditional litigation system does meet the requirement of digitalised of society. This article discusses the concept of AI on supporting dispute resolution system that will assisting in offering an efficient, cost effective, time saving solution to parties.

\section{References}

Aamodt A and Plaza E, (1994) 'Case-Based Reasoning: Foundational Issues, Methodological Variations, And System Approaches' 7 Journal AI Communications

Allwood W, 'Expert Systems In Law; A Jurisprudential Inquiry' (1989) 47 The Cambridge Law Journal Business Dictionary, 'Knowledge Based System' <http://www.businessdictionary.com/definition/knowledge-based-system.html> accessed 17 November 2019

BBC, 'Ebay In $\$ 925 \mathrm{M}$ Disposal As Paypal Spin-Off Nears' (2015) <http://www.bbc.co.uk/news/business-33557668> accessed 6 April 2019

Bock P, 'The Emergence Of Artificial Intelligence: Learning To Learn' [1985] AI Magazine

Cambridge Dictionaries Online, Artificial Intelligence' <http://dictionary.cambridge.org/dictionary/english/artificial-intelligence> accessed 11 November 2019 
Carneiro D and others, (2014) 'Online Dispute Resolution: An Artificial Intelligence Perspective' 41 Artif Intell Rev

Choudhary D, Lather A and Kalra N, (2015) 'Artificial Intelligence and Online Dispute Resolution' 1 International Journal of Innovative Research in Technology

Cortés P, (2011) Online Dispute Resolution For Consumers In The European Union, Routledge 2011

Cortes P, (2014) 'Online Dispute Resolution Services: A Selected Number of Case Studies' 6 Computer and Telecommunications Law Review

eBay, 'Ebay Resolution Center' <http://resolutioncentre.ebay.co.uk/> accessed 5 November 2019

eBay, 'Who we are' < https://www.ebayinc.com/our-company/who-we-are/> accessed 4 January 2019

Global Connected and IoT Device Forecast Update 2019) < https://www.strategyanalytics.com/accessservices/devices/connected-home/smart-home/reports/report-detail/global-connected-and-iotdevice-forecast-update?slid=1051315\&spg=3> accessed 5 April 2019

Kolodner J, (1992) 'An Introduction To Case-Based Reasoning' 6 Artificial Intelligence Review

Larson D, (2010) 'Artificial Intelligence: Robots, Avatars, And The Demise Of The Human Mediator' 25 Ohio State Journal On Dispute Resolution

Lodder A and Thiessen E, [2003] 'The Role Of Artificial Intelligence In Online Dispute Resolution' Proceedings of the UNECE Forum on ODR $2003<$ http://www.odr.info/unece2003> accessed 25 October 2015

Lodder A and Zeleznikow J, 'Developing An Online Dispute Resolution Environment: Dialogue Tools And Negotiation Support Systems In A Three-Step Model' (2005) 10 Harvard Negotiation Law Review

Lodder A and Zeleznikow J, (2012) 'Artificial Intelligence and Online Dispute Resolution` in Mohamed S.Abdel Wahap and others (eds), Online Dispute Resolution: Theory and Practice `A Treatise on Technology and Dispute Resolution ` (Eleven International Publishing)

Markoff J, 'Scientists Worry Machines May Outsmart Man' (The New York Times, 2009) <http://www.nytimes.com/2009/o7/26/science/26robot.html?_r=o> accessed 17 November 2019

McCarthy J, (2019) 'What Is Artificial Intelligence?' [2007] Stanford University

PayPal, 'Who We Are' < https://www.paypal.com/gi/webapps/mpp/about > accessed 6 April 2019.

Postman N, 'Five Things We Need To Know About Technological Change' <http://www.mat.upm.es/ jcm/neil-postman--five-things.html> accessed 20 November 2019

Rabinovich-Einy O and Katsh E, (2012) 'Technology And The Future Of Dispute Systems Design' 17 Harvard Negotiation Law Review

Raymond A and Stemler A, (2015) 'Trusting Strangers: Dispute Resolution in The Crowd' 16 Cardozo Journal of Conflict Resolution

Raymond A, (2014) 'Yeah, But Did You See The Gorilla? Creating And Protecting' 18 Harvard Negotiation Law Review

Rich C and Sidner C, [2009] 'Robots And Avatars As Hosts, Advisors,Companions, And Jesters' AI Magazine

Rule C, [2015] 'Technology And The Future Of Dispute Resolution' Dispute Resolution Magazine

Sajja P and Akerkar R, (2010) 'Knowledge-Based Systems For Development' 1 Advanced Knowledge Based Systems:Model, Applications \& Research

SCIENCE DAILY, (2008) 'Military Use Of Robots Increases' <http://www.sciencedaily.com/releases/2008/o8/o80804190711.htm> accessed 25 November 2019

SquareTrade, 'Does Squaretrade Offer Dispute Resolution Or Mediation Services?' <http://squaretrade.force.com/support/faqArticles/Does-SquareTrade-offer-dispute-resolution- 
or-mediation-services $>$ accessed 5 November 2019

Susskind R, Expert Systems in Law; A Jurisprudential Inquiry (Clarendon Press 1987)

Susskind R, (1988) Expert Systems in Law; a Jurisprudential Inquiry in Clark A(ed) in 15 Journal of Law and Society, <http://www.jstor.org/stable/1410151> accessed 12 November 2019.

The History of eBay (2015) <http://www.cs.brandeis.edu/ magnus/ief248a/eBay/history.html> accessed 4 November 2019

The Internet Corporation for Assigned Names and Numbers (ICANN), 'ICANN' (2015) <https://www.icann.org/> accessed 9 November 2019.

WIPO, 'What Is WIPO?' (2015) <http://www.wipo.int/about-wipo/en/index.html> accessed 9 November 2019.

WIPO, 'What Is the WIPO Arbitration and Mediation Center?' (2015) <http://www.wipo.int/amc/en/center/faq/index.html> accessed 9 November 2019

WIPO, 'Report Of The Director General To The WIPO Assemblies' (2015) <http://www.wipo.int/edocs/pubdocs/en/wipo_pub_1050_15.pdf> accessed 10 November 2019.

WIPO Guide to the Uniform Domain Name Dispute Resolution Policy (UDRP)

WIPO, 'The 2014 WIPO Mediation, Arbitration, Expedited Arbitration And Expert Determination Rules' <http://www.wipo.int/amc/en/domains/gtld/> accessed 10 November 2019.

WIPO Domain Name Dispute Resolution Statistics https://www.wipo.int/amc/en/domains/statistics/> accessed 6 April 2019

WIPO General Assembly, 'WIPO ARBITRATION AND MEDIATION CENTER, INCLUDING DOMAIN NAMES' (2015) <http://www.wipo.int/edocs/mdocs/govbody/en/wo_ga_47/wo_ga_47_14.pdf> accessed 10 November 2019.

World Internet Users Statistics and 2019 World Population Stats. (2019) < https://www.internetworldstats.com/stats.htm> accessed 15 April 2019 